\title{
Produção científica dos docentes da Universidade Federal da Bahia da área de Filosofia e Ciências Humanas no período de 1995-1999
}

\author{
Analysis of the professors' scientific production in the \\ field of Philosophy and Humanities at the Federal \\ University of Bahia (Brazil), during 1995-1999
}

Raymundo das Neves MACHADO ${ }^{1}$

Rodrigo França MEIRELLES²

R E S U M O

Estudo realizado na Universidade Federal da Bahia, com o objetivo de conhecer e identificar os principaís produtores de conhecimentos na área de Filosofia e Ciências Humanas daquela entidade, bem como os veículos utilizados para a transferência do conhecimento gerado. Para a coleta dos dados foi utilizado o Catálogo de Produção Científica, Literária e Artística, 1994-1996, complementado pelo Sistema Produção Docente. O período estudado foi de cinco anos (1995-1999). Os resultados apontam que, do universo de 372 docentes, 63,17\% foram responsáveis por um total de 2083 publicações, entre livros, capítulos de livros, artigos de periódicos, comunicações em eventos e outros. O meio de maior divulgação da produção científica foi o artigo de periódico com 33,41\%; seguido das comunicações em eventos, com 18,24\%; livros, 4,85\%; e capítulos de livro, com $13,59 \%$. O português foi o idioma de maior incidência com $96,54 \%$ da produção científica.

Palavras-chave: produção científica, filosofia e ciências humanas.

\footnotetext{
${ }^{1}$ Mestre, Docente Assistente, Departamento de Biblioteconomia do Instituto de Ciência da Informação, Universidade Federal da Bahia. Av. Reitor Miguel Calmon, s/n, Campus Universitário do Canela, 40110-100, Salvador, BA, Brasil. Correspondência para/Correspondence to: R.N. MACHADO.E-mail: <raymacha@ufba.br>.

2 Acadêmico, Curso de Biblioteconomia e Documentação, Universidade Federal da Bahia. Bolsista de Iniciação Científica UFBA/PIBIC/FAPESB. E-mail: <rodrigomei@bol.com.br>.

Recebido em 8/9/2004 e aceito para publicação em 24/5/2005.
} 
A B S T R A C T

Analysis carried out at the Federal University of Bahia, with the objective of identifying the main knowledge producers in the field of Philosophy and Humanities at that institution, as well as the media used to publicize the generated knowledge. Data was collected from the Catalogue of Scientific, Literary and Artistic Production, 1994-1996 and complemented with the System on Academic Body Production. The study covered a five-year period, from 1995 to 1999. The results indicate that out of the universe of 372 professors, $63.17 \%$ were responsible for a total of 2083 publications, amongst books, book chapters, articles in periodicals, conference papers, and others. The most frequently used means of disclosure of the scientific production was the article in periodicals, representing $33.41 \%$ of the publications, and followed by the presentation of papers in events (18.24\%); next, came books (4.85\%) and book chapters (13.59\%), Portuguese was the most frequently used language, representing $96.54 \%$ of the scientific production.

Key words: scientific production, philosophy and humanities.

\section{N T R O D U Ç Ã O}

A produção científica representa uma parte materializada do conhecimento gerado e sua disseminação constitui a socialização do saber. Para Lima et al. (1998), o conhecimento deverá estar disponível, ser de fácil acesso e divulgado para a sociedade, que fará uso dele em seu próprio benefício. Para tanto, é indispensável a sua publicação, atividade com que se deve ocupar o pesquisador. Sinaliza Velho (1997, p.17) que o "ato de publicar é parte constituinte do conceito de pesquisador", ressaltando o papel deste em disponibilizar o conhecimento gerado.

O pesquisador é reconhecido por meio de sua produção científica, ou seja, pela quantidade/qualidade de trabalhos publicados, em todos os formatos, em determinado período de tempo. Essa produção está estreitamente ligada à comunicação científica. No Brasil, o maior número de pesquisadores é formado por professores e alunos dos cursos de pós-graduação, responsáveis pela geração da maior parte da produção científica nacional. Esclarece Witter (1997, p.29) que "a pesquisa científica de um país está muito relacionada com a atuação dos cursos de pós-graduação, quer pelo fazer científico dos mesmos quer pelo papel na formação de pesquisadores que irão atuar em outras entidades universitárias, ou não"; tais cursos têm, assim, papel fundamental na disseminação dos resultados de pesquisa na universidade, fazendo avançar o conhecimento gerado dentro da própria instituição. Para Meis e Leta, (1996, p.33) "a pesquisa científica dentro da universidade desempenha papel importante não só na produção de novos conhecimentos, mas também na capacitação de tornar accessíveis aos seus estudantes os avanços contínuos do saber".

Com o estudo da produção científica podemos determinar, por exemplo, qual a frente de pesquisa de uma determinada área, quais os autores e instituições mais produtivas, e quais as características das áreas do conhecimento humano. Esses dados são verdadeiros indicadores de produtividade, servindo de informações para as agências de fomento à pesquisa e para a própria instituição na qual a produção é gerada.

Estudos de produção científica são realizados por pesquisadores da Ciência da Informação. Targino e Caldeira (1988) desenvolveram um estudo em que avaliaram a produção científica da Universidade Federal do Piauí (UFPI), 
publicada no período de 1984 a 1999. Os resultados da pesquisa indicaram que apenas $9,92 \%$ dos docentes apresentaram contribuições, em média, 0,92\% trabalho por pessoa; desta forma, constatou-se a necessidade de adoção de medidas que gerem o desenvolvimento de pesquisas com o fim de aumentar a produção científica de seus docentes. Os artigos de periódicos, juntamente com os trabalhos apresentados em eventos científicos, foram os veículos mais utilizados pelos docentes. O idioma português foi o que predominou em toda a literatura produzida.

Oliveira e Aragão (1992) estudaram a produção científica da Universidade Federal da Bahia (UFBA), no período de 1979-1988, com dois enfoques: o primeiro estudou a produção geral da universidade e o segundo enfatizou a produção dos professores da Faculdade de Medicina. As áreas de Ciências Biológicas e Profissões da Saúde foram as de maior produção, com destaque para Medicina. Aárea de Filosofia e Ciências Humanas foi a segunda colocada, tendo a Educação o maior índice de produtividade. As comunicações apresentadas em eventos científicos, seguidos dos artigos de periódicos, foram os meios de disseminação do conhecimento mais utilizados pelos docentes da UFBA no período estudado.

Na Pontifícia Universidade Católica de Campinas (PUC-Campinas) foi desenvolvido um estudo por Lima et al. (1998), no qual foi comparada a produção científica de quatro unidades de ensino: Biblioteconomia, Educação, Filosofia e Psicologia. As conclusões do estudo revelam a necessidade de um estudo mais detalhado sobre o tipo e prática de produção dos docentes da PUC-Campinas. A Faculdade de Psicologia obteve a maior taxa de produção no período estudado, 1990-1994. Com relação ao veículo de publicação, o periódico foi o mais utilizado.

A pesquisa desenvolvida por Meis e Leta (1996) traçou o perfil da ciência brasileira no período de 1981 a 1993. Os resultados sinalizam um crescimento da pesquisa científica no que tange a trabalhos publicados em nível nacional e internacional. As áreas de maior destaque foram: Ciências Biológicas (Agricultura/Agronomia, 33,2\%), Ciências Biomédicas (Biologia Experimental e Medicina, 36,7\%), Medicina (Medicina Clínica, 27,6\%), Medicina Social (mais de 70,0\% vem da Saúde Pública), Ciências Exatas (Físico-Química, 30,6\%), Física (com 40,6\%), Matemática (92,0\%), Ciência do Espaço $(31,8 \%)$ e Ciências Humanas e Artes (Sociologia/ Antropologia/Lingüística, $25,8 \%$ do total de artigos da área). Segundo a pesquisa supracitada, o perfil da produção das ciências humanas e das artes permaneceu constante no período, com uma produção apresentando altos e baixos.

O objetivo do presente trabalho foi estudar a produção científica da UFBA, durante o período de 1995 a 1999, na Área de Filosofia e Ciências Humanas, identificando os principais produtores de conhecimentos nessa área, a titulação desses pesquisadores e quais os veículos de maior preferência dos docentes para disseminar o conhecimento produzido. Ademais, verificou-se qual o idioma mais usado para essas publicações, o departamento com a maior taxa de produtividade e qual o ano com maior índice de produção.

\section{M É T O D O S}

O método empregado para o desenvolvimento da pesquisa foi o quantitativo, uma vez que a produção científica pode ser mensurada. Os dados foram distribuídos em categoriais específicas, o que permitiu uma aferição mais acurada deles.

A Área de Filosofia e Ciências Humanas da Universidade Federal da Bahia, compreende 16 cursos de graduação (Administração, Secretariado Executivo, Biblioteconomia e Documentação, Arquivologia, Ciências Econômicas, Ciências Contábeis, Comunicação-Jornalismo, Comunicação-Produção Cultural, Direito, 
Pedagogia, Educação Física, Filosofia, História, Museologia, Psicologia, Ciências Sociais), 13 programas de pós-graduação (mestrado e doutorado), 21 departamentos distribuídos em oito unidades de ensino, com um total de 372 docentes.

O material utilizado para coleta dos dados foram duas fontes de informação. Foi utilizado, para o período de 1995 a 1996, o Catá-logo da Produção Científica, Literária e Artística, UFBA, editado em 1997 pela Pró-Reitoria de Pesquisa e Pós-Graduação. Para o período de 1997 a 1999 foi utilizado o Sistema de Produção Docente (SIDoc) (http://www.ufba.br/instituicoes/ufba/ orgaos/cpd/sistemas/sidoc), uma vez que o catálogo deixou de ser publicado em 1997. O SIDoc é um instrumento de uso interno da UFBA, com objetivos bem diferentes do Catálogo. Portanto, foi também realizada uma análise destes instrumentos, verificando-se os elementos comuns aos dois.

Para atingir o objetivo proposto para este estudo, realizou-se o levantamento dos dados no Catálogo da Produção Científica, Literária e Artística, UFBA para o período de 1995 a 1996, e no SIDoc para o período de 1997 a 1999. Após análise e comparação das duas fontes utilizadas, uma vez que a segunda fonte não apresentava, como a primeira, o registro da publicação completo, optou-se por usar elementos comuns às duas fontes. As seguintes variáveis foram estudas: titulação dos docentes, tipologia das fontes, idioma das fontes, categoria dos produtores, ano de produção, departamentos mais produtivos. Os dados foram levantados pela relação nominal dos professores, fornecida pela Superintendência de Pessoal/UFBA. Para uma melhor tabulação e análise dos dados, foram confeccionadas planilhas eletrônicas utilizando o Microsoft Excel (2000).

A Área de Filosofia e Ciências Humanas, da Universidade Federal da Bahia, conta com
16 cursos de graduação, 13 programas de pós-graduação (mestrado e doutorado) e 21 departamentos distribuídos em oito unidades de ensino, com um total de 372 docentes $^{3}$. No que tange à titulação dos docentes (Figura 1), podemos observar que há um equilíbrio entre o número de mestres (41\%) e doutores (41\%), porém, o número de professores com graduação $(11 \%)$ é superior aos que têm titulação de especialista (7\%). Podemos concluir que a Área de Filosofia e Ciência Humanas/UFBA possui um corpo docente qualificado, sendo que $89 \%$ dos docentes possuem pós-graduação e apenas $11 \%$ a graduação.

No período de 1995-1999, os docentes produziram um total de 2083 publicações nas categorias: livros, capítulos de livros, artigos de periódicos, comunicações em eventos científicos, matérias em jornais e revista de grande circulação.

A Tabela 1 sinaliza que os docentes com doutorado são os que possuem maior número de produções, perfazendo um total de 1593 publicações (76,48\%), seguidos pelos docentes com mestrado com 417 produções $(20,02 \%)$. Os professores doutores são os responsáveis pelo maior índice de publicações da Área de Filosofa e Ciências Humanas/UFBA; esses docentes geralmente são vinculados aos programas de pós-graduação (mestrado e doutorado) e, além de ministrar aulas, desenvolvem pesquisa, gerando conhecimento.

Os docentes com graduação foram responsáveis por um total de 54 (2,59\%) trabalhos, número superior aos docentes com titulação de especialização, que tiveram uma freqüência absoluta de 19 publicações (0,91\%).

A Área de Filosofia e Ciências Humanas, UFBA apresentou uma média de 416,6 trabalhos no período pesquisado. Já os docentes alcançaram uma média de 5,59 trabalhos publicados no período de 1995-1999.

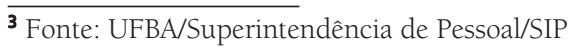




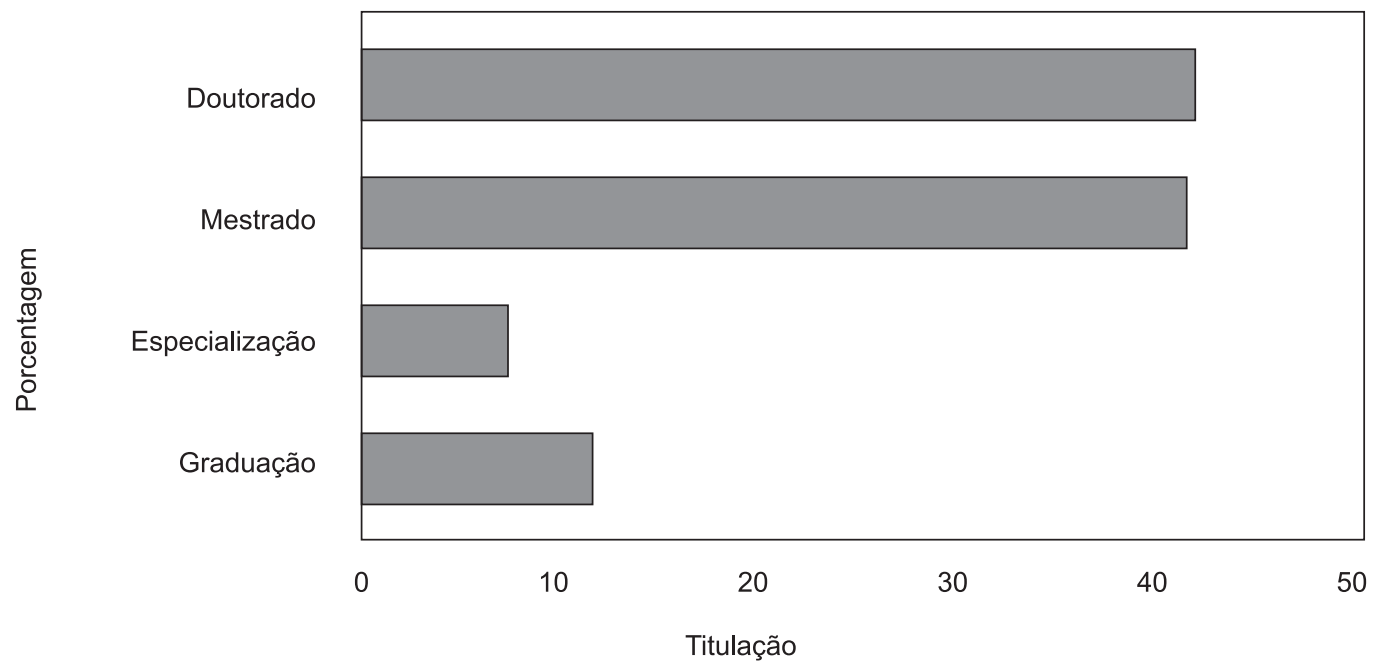

Figura 1. Titulação dos Professores da Área de Filosofia e Ciência Humanas da UFBA Período de 1995-1999.

Tabela 1.Produção por Titulação dos Docentes da Área de Filosofia e Ciências Humanas/UFBA, Período 1995-1999.

\begin{tabular}{|c|c|c|c|}
\hline \multirow{2}{*}{ Titulação } & \multicolumn{2}{|c|}{ Produção } & \multirow{2}{*}{ Média no Período } \\
\hline & Absoluta & Relativa & \\
\hline Graduação & 54 & 2,59 & 10,8 \\
\hline Especialização & 19 & 0,91 & 3,8 \\
\hline Mestrado & 417 & 20,02 & 83,4 \\
\hline Doutorado & 1593 & 76,48 & 318,6 \\
\hline Total & 2083 & 100,00 & \\
\hline
\end{tabular}

A Tabela 2 apresenta o total de docentes por titulação, bem como os docentes com e sem publicação dentro de cada categoria. O número de professores-doutores é de 152, representando $40,92 \%$ do total geral, sendo este o grupo com o maior índice de produtividade, ou seja, responsável por $57,87 \%$ da produção.

A produtividade dos Departamentos foi mensurada em três níveis: absoluta, relativa e acumulada. Assim, dos 21 departamentos da Área de Filosofia e Ciência Humanas, UFBA (Tabela 3), cinco apresentaram o maior número de produção que, em conjunto, somaram um total de $1032(49,54 \%)$ publicações, sendo três deles da Faculdade de Filosofia e Ciências Humanas (Psicologia, Sociologia, e Antropologia e Etnologia). O departamento de Psicologia foi responsável por $10,56 \%$ do total da produção científica, apresentando uma média de 44 trabalhos no período estudado. Observa-se que no estudo de Lima et al. (1998) a Psicologia, da PUC-Campinas, também alcançou um alto grau de produção, ou seja, $63,8 \%$ em relação às outras unidades estudadas.

O Departamento de Comunicação, com $10,23 \%$, foi o segundo colocado, seguido pelo 
Tabela 2. Número de Produtores e Não-Produtores da Área de Filosofia e Ciências Humanas/UFBA. Período 1995-1999.

\begin{tabular}{|c|c|c|c|c|c|c|}
\hline \multirow{2}{*}{ Titulação } & \multicolumn{2}{|c|}{ Docentes } & \multicolumn{2}{|c|}{ Produtores } & \multicolumn{2}{|c|}{ Não Produtores } \\
\hline & $f^{*}$ & $\%$ & $f^{*}$ & $\%$ & $f^{*}$ & $\%$ \\
\hline Graduação & 42 & 11,29 & 17 & 7,23 & 25 & 18,25 \\
\hline Especialização & 27 & 7,26 & 6 & 2,55 & 21 & 15,33 \\
\hline Mestrado & 151 & 40,59 & 76 & 32,35 & 75 & 54,74 \\
\hline Doutorado & 152 & 40,86 & 136 & 57,87 & 16 & 11,68 \\
\hline Total & 372 & 100,00 & 235 & 100,00 & 137 & 100,00 \\
\hline
\end{tabular}

*Freqüência.

Tabela 3. Produção por Departamento da Área de Filosofia e Ciências Humanas/UFBA. Período de 1995-1999.

\begin{tabular}{|c|c|c|c|c|}
\hline \multirow{2}{*}{ Departamentos } & \multicolumn{3}{|c|}{ Produção } & \multirow{2}{*}{ Média Anual } \\
\hline & Absoluta & Relativa & Acumulada & \\
\hline Psicologia & 220 & 10,56 & 10,6 & 44,0 \\
\hline Comunicação & 213 & 10,23 & 20,8 & 42,6 \\
\hline Sociologia & 207 & 9,94 & 30,7 & 41,4 \\
\hline Educação I & 202 & 9,70 & 40,4 & 40,4 \\
\hline Antropologia e Etnologia & 190 & 9,12 & 49,5 & 38,0 \\
\hline Teoria Econômica & 148 & 7,11 & 56,6 & 29,6 \\
\hline Educação II & 100 & 4,80 & 61,4 & 20,0 \\
\hline Finanças e Políticas Públicas & 96 & 4,61 & 66,1 & 19,2 \\
\hline História & 96 & 4,61 & 70,7 & 19,2 \\
\hline Filosofia & 94 & 4,51 & 75,2 & 18,8 \\
\hline Ciência Política & 84 & 4,03 & 79,2 & 16,8 \\
\hline Estudos Organizacionais & 73 & 3,50 & 82,7 & 14,6 \\
\hline Documentação e Informação & 56 & 2,69 & 85,4 & 11,2 \\
\hline Economia Aplicada & 51 & 2,45 & 87,9 & 10,2 \\
\hline Educação III & 46 & 2,21 & 90,1 & 9,2 \\
\hline Biblioteconomia & 46 & 2,21 & 92,3 & 9,2 \\
\hline Direito Privado & 44 & 2,11 & 94,4 & 8,8 \\
\hline Direito Público & 44 & 2,11 & 96,5 & 8,8 \\
\hline Sistemas e Proce. Gerais & 38 & 1,82 & 98,3 & 7,6 \\
\hline Museologia & 24 & 1,15 & 99,5 & 4,8 \\
\hline Contabilidade & 11 & 0,53 & 100,0 & 2,2 \\
\hline Total & 2083 & 100 & & \\
\hline
\end{tabular}

Departamento de Sociologia, com 9,94\%. O Departamento de Educação I, com 9,70\%, foi o quarto colocado e o Departamento de Antropologia e Etnologia obteve a quinta colocação, com $9,12 \%$.
Observando os resultados da freqüência acumulada superior da Tabela 3, observa-se que os departamentos de Psicologia, Comunicação, Sociologia, Educação I e Antropologia e Etnologia contribuíram com cerca de $50 \%$ da 


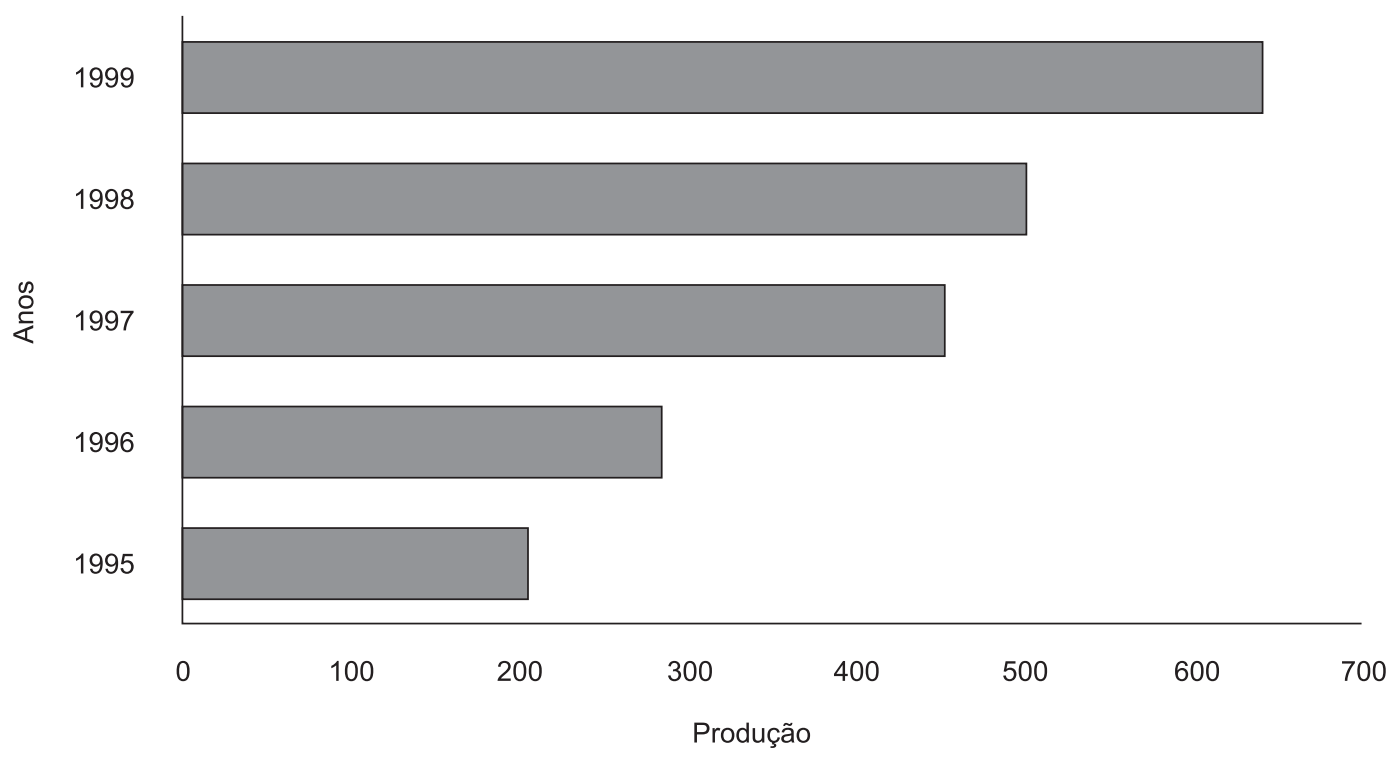

Figura 2. Distribuição Anual da Produção Científica da Área de Filosofia e Ciências Humanas/UFBA. Período 1995-1999.

produção. Em seguida, o Departamento de Teoria Econômica produziu $7,11 \%$, enquanto a produção de cada um dos demais departamentos foi inferior a $5 \%$.

À distribuição anual da produção dos docentes (Figura 2), observa-se que essa se encontra em ordem crescente. Através de regressão linear simples, considerando-se a produção total como variável dependente e o ano como variável preditora, observou-se uma taxa anual média de crescimento de 95 publicações por ano.

Observamos (Figura 3) que o artigo de periódico foi o meio mais utilizado para divulgação dos estudos/pesquisas dos docentes da Área de Filosofia e Ciências Humanas, UFBA. No total, foram 696 ocorrências (33,41\%), com uma média de 139,20 artigos no período estudado.

Em uma pesquisa realizada por Stumpf (2000), os artigos de periódicos foi o canal que apresentou o maior índice de publicações pelos docentes da área de Ciências Humanas da UFRGS. A preferência por esse tipo de veículo se deve pela rápida difusão que ele tem na comunidade científica (OHIRA, 1997).

As comunicações em eventos apresentaram 380 ocorrências, correspondendo a $18,24 \%$ do total geral. Essa análise leva a inferir que os eventos científicos são meios de divulgação dos resultados das pesquisas, estudos e trabalhos desenvolvidos pelos docentes. Esses eventos propiciam o intercâmbio entre pesquisadores e, conseqüentemente, impulsiona a comunicação científica.

No estudo realizado por Oliveira e Aragão (1992), a comunicação apresentada em eventos científicos foi a preferida pelos docentes da UFBA no período de 1979-1988. Segundo as autoras, isso se deve "ao esforço da UFBA junto à comunidade acadêmica, estimulando sua participação em encontros, seminários e congressos de natureza científica." (OLIVEIRA; ARAGÃO, 1992, p.207). Nesse mesmo trabalho, os artigos de periódico aparecem em segundo lugar.

O livro, considerado como veículo de grande materialização do conhecimento da área 
de Ciências Humanas, apresentou um total de 101 ocorrências (4,85\%). O capítulo de livro apresentou 283 publicações (13,59\%). Para Meadows (1999) e Velho (1997), os pesquisadores de Humanidades e Ciências Humanas preferem disseminar os resultados de suas pesquisas em livros, fato esse não observado na comunidade científica da Área de Filosofia e Ciências Humanas, UFBA, no período estudado. Esse tipo de publicação apresenta certos tipos de dificuldades, como, por exemplo, recursos financeiros, linha editorial, o tempo dedicado para escrever e revisar o texto. O capítulo de livro obteve uma representatividade maior do que 0 livro, devido às coletâneas organizadas e publicadas no período estudado, uma vez que esse tipo de publicação reune vários trabalhos de diferentes autores.

As matérias veiculadas em jornais diários obtiveram 4,05\% do total das publicações; já as revistas (magazines) foram responsáveis por $1,29 \%$. Na categoria "outras publicações" $(25,88 \%)$ foram consideradas produções do tipo: resumos, traduções, relatórios.

Na Figura 4 podemos visualizar como a tipologia se comporta a partir do momento que a produção total cresce. Para tanto, utilizamos a Regressão Logística com variável resposta categórica. Essa técnica foi empregada para que fosse possível encontrar a tendência provável (probabilidade) de cada tipologia, em função do

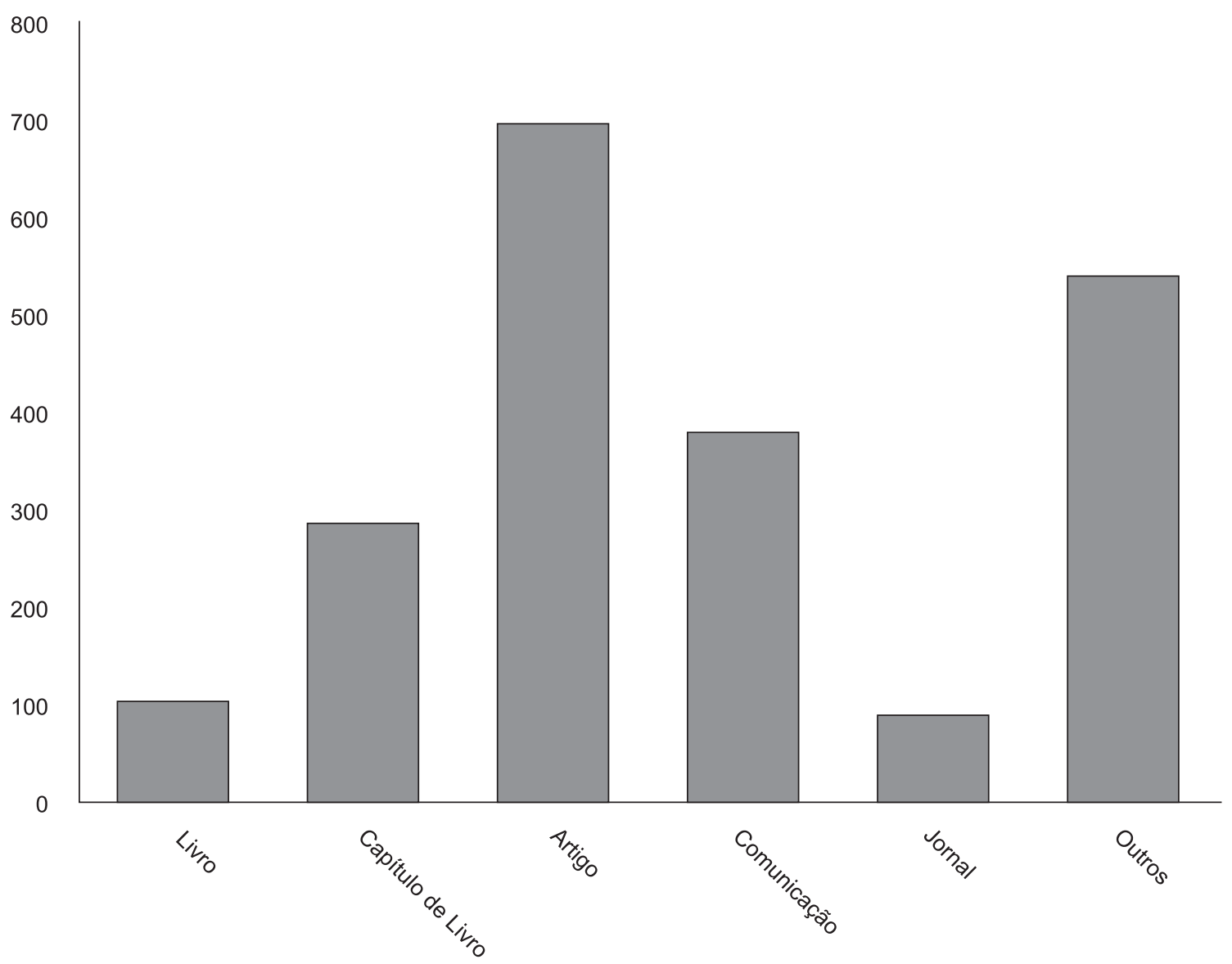

Figura 3. Tipologia das Fontes Utilizadas pelos Docentes da Área de Filosofia e Ciências Humanas da UFBA. Período de 1995-1999. 


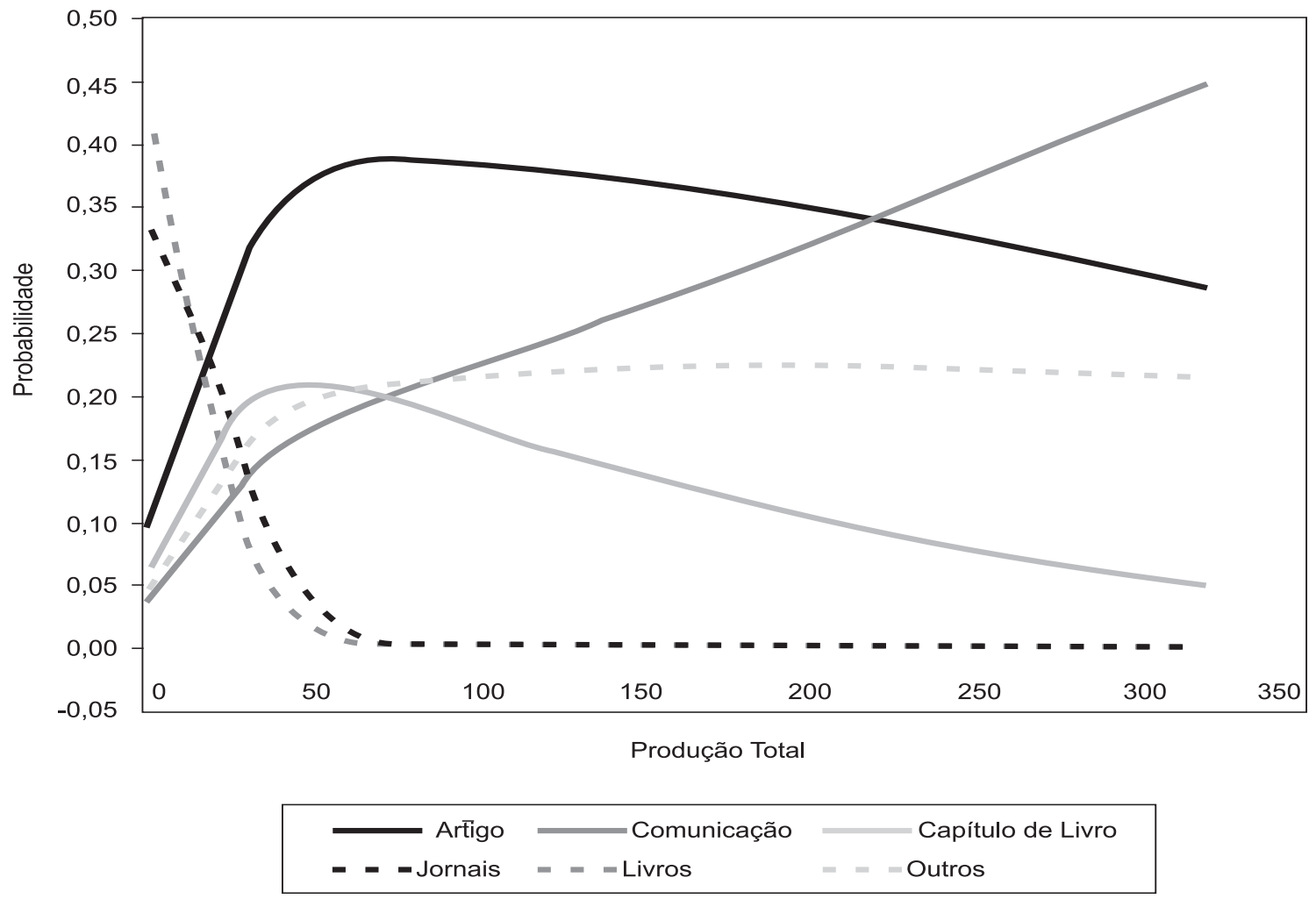

Figura 4. Probabilidade de crescimento da Produção Bibliográfica da Área de Filosofia e Ciências Humanas, UFBA. Período 1995-1999.

crescimento da produção científica na UFBA. Assim, ficou facilmente observado que a probabilidade de artigo de periódico ser produzido aumenta quando a produção total cresce, enquanto capítulo de livro, comunicação em eventos e outros tipos de publicações têm uma tendência inicial de crescimento, mas decrescem a partir do momento em que a produção total começa a ser ampliada; já jornal e livro têm as suas probabilidades de serem produzidos sempre em ordem decrescente.

Os dados numéricos desta modelagem mostraram que, para cada aumento unitário na produção bibliográfica, a chance de ser um artigo é 1.08 vezes maior que a de ser livro, ou seja, para cada unidade produzida, a chance de ser artigo é $8 \%$ maior do que a de ser livro.
Com relação ao idioma dos trabalhos produzidos pelos docentes da Área de Filosofia e Ciências Humanas, UFBA, o português obteve uma freqüência de 2.011, o que equivale a $96,54 \%$, dado também encontrado na pesquisa de Oliveira e Aragão (1992). Em seguida veio o inglês, com 34 publicações (1,63\%), o espanhol, com $20(0,96 \%)$, e o francês, com $9(0,43 \%)$. Observa-se, então, uma tímida penetrabilidade da produção científica no cenário internacional.

Para uma melhor compreensão dos produtores foram criadas quatro categorias (Tabela 4), ou seja: grandes produtores, produtores moderados, transeuntes e ocasionais. $\mathrm{Na}$ primeira categoria, três professores se destacaram com um total de 160 trabalhos publicados. A média de produção foi da ordem de 53,33 trabalhos ao ano. 
Tabela 4. Categoria dos Produtores da Área III /UFBA. Período 1995-1999.

\begin{tabular}{|c|c|c|c|c|c|}
\hline \multirow{2}{*}{ Categorias } & \multicolumn{2}{|c|}{ Autores } & \multicolumn{2}{|c|}{ Trabalhos } & \multirow{2}{*}{$\begin{array}{l}\text { Produtividade } \\
\text { Média Anual }\end{array}$} \\
\hline & $f$ & $\%$ & $f$ & $\%$ & \\
\hline Grandes produtores (+ 40 trabalhos) & 3 & 1,27 & 160 & 7,67 & 53,33 \\
\hline Produtores Moderados (entre 15 e 40 trabalhos) & 40 & 17,02 & 929 & 44,55 & 23,22 \\
\hline Transeuntes (entre 9 a 14 trabalhos) & 37 & 15,74 & 406 & 19,48 & 10,97 \\
\hline Ocasionais (até 8 trabalhos) & 155 & 65,95 & 588 & 28,30 & 3,79 \\
\hline Total & 235 & 100,0 & 2083 & 100,0 & - \\
\hline
\end{tabular}

$\mathrm{Na}$ categoria produtores moderados, foram alocados os docentes com uma produção entre 15 a 40 trabalhos. Essa categoria foi a de maior representatividade na produção, com 929 trabalhos publicados por 40 docentes, tendo uma média de 23,22 publicações ao ano.

Os demais docentes com uma variação de produção entre 9 a 14 publicações foram classificados como transeuntes, com um total de 37 docentes que, em conjunto, publicaram 406 trabalhos. Observa-se que na categoria ocasionais encontra-se a maioria dos docentes (65,95\%), com uma produtividade média de 3,79 trabalhos.

A Tabela 4 apresentou uma característica dos docentes da Área de Filosofia e Ciências Humanas, UFBA, ou seja, $(65,95 \%)$ são produtores ocasionais. A elite da área é formada por autores com alta produtividade, composta apenas por três docentes, todos com grau de doutor que, em conjunto, produziram 160 trabalhos, resultando numa média de 53,33 publicações por produtor. Observa-se que um quinto dos docentes foram responsáveis por mais da metade de toda a literatura gerada no período estudado.

\section{O N C L U S Ã O}

A pesquisa demonstrou que no período de 1995-1999 a produção do corpo docente da Área de Filosofia e Ciências Humanas, UFBA foi diversificada. Os docentes utilizaram vários canais para publicar os resultados de suas pesquisas, trabalhos e estudos. De um total de 372 professores, 63,17\% (235) foram responsáveis por 2.083 publicações com uma média de 8,86 trabalhos por docente.

Este estudo possibilitou conhecer mais de perto a atividade de produção dos docentes da Área de Filosofa e Ciências Humanas, UFBA. Estudos desta natureza são relevantes, pois proporcionam análises das tendências em determinadas áreas do conhecimento.

No estudo em foco, a produção dos docentes foi de ordem exponencial, com uma taxa anual média de crescimento de 95 publicações por ano, tendo no artigo de periódico o canal de maior preferência dos docentes para disseminar sua produção científica.

Com relação ao material utilizado para a coleta de dados, isto é, o Catálogo da Produção Científica, Literária e Artística, UFBA para o período de 1995 a 1996 e o SIDoc para o período de 1997 a 1999, ambas apresentam características peculiares. O primeiro tem objetivo de tornar visível a produção gerada na UFBA. O segundo tem um caráter específico, pois é de uso interno. O catálogo deixou de ser publicado em 1997, criando-se desse modo uma lacuna e impossibilitando o acesso à produção gerada na UFBA. Já o SIDoc, é instrumento mais restrito, com dados muito resumidos, o que dificulta a análise mais detalhada; nele é impossível identificar, por exemplo, a co-autoria, uma variável que contribuiria para os estudos de integração em níveis intradepartamental, interdepartamental e interins- 
titucional (nacional e internacional). Segundo observa Meadows (1999 p.109), "a literatura gerada por pesquisas feitas em colaboração mostra diferenças importantes se comparada à produzida por pesquisadores que trabalham isoladamente".

O estudo da produção científica de uma instituição deve ir além do aspecto quantitativo: deve-se também verificar o impacto da produção

\section{R E FER Ê N CIAS}

LIMA, M.F. et al. Produção científica: tipologia e autoria de publicações de docentes da PUC-Campinas (1990-1994). Transinformação, Campinas, v.19, n.1, p.120-131, 1998.

MEADOWS, A.J. A comunicação científica. Brasília: Briquet de Lemos/Livros, 1999.

MEIS, L.; LETA, J. O perfil da ciência brasileira. Rio de Janeiro: Editora UFRJ, 1996.

MICROSOFT Excel 2000. Version 7 [S.I.]: Microsoft Corporation, 1999.

OHIRA, M.L.B. Produção técnico-científica e artística da Universidade Federal de Santa Catarina (1991-1995). In: WITTER, G.P. (Org.). Produção científica. Campinas: Átomo, 1997. p.87-113.

OLIVERIA, M.P.; ARAGÃO, E.M. Padrões de comunicação científica na Universidade Federal da gerada no âmbito nacional. Estudo desse porte deverá ser realizado como complementação do presente trabalho, para possibilitar melhor compreensão do campo de conhecimento em questão. Entretanto, espera-se que o presente estudo, apesar das suas limitações, contribua para um melhor entendimento da produção científica na Área Filosofa e Ciências Humanas da Universidade Federal da Bahia.

Bahia. Ciência da Informação, Brasília, v.21, n.3, p.201-215, 1992.

STUMPF, I.R.C. A comunicação da ciência na universidade: o caso da UFGRS. In: MUELLER, S.P.M.; PASSOS, E.J.L. (Org.). Comunicação científica. Brasília: Universidade de Brasília, 2000. p.1078-1121.

TARGINO, M.G.; CALDEIRA, P.T. Análise da produção científica de uma instituição de ensino superior: 0 caso da Universidade Federal do Piauí. Ciência da Informação, Brasília, v. 17, n.1, p.15-25, 1988.

VELHO, L. A ciência e seu público. Transinformação, Campinas, v.9, n.3, p.15-32, 1997.

WITTER, G.P. (Org.). Produção científica. Campinas: Átomo, 1997. 
